\title{
SMART HOME WITH SMART CONTROL, BERBASIS BLUETOOTH MIKROKONTROLLER
}

\author{
Barep adi jaya ${ }^{1)}$, amalia herlina ${ }^{2)}$, Sherly ferdiant ${ }^{3)}$ \\ Prodi Teknik ElektroFakultas Teknik Universitas Nurul Jadid \\ Karanganyar Paiton Probolinggo \\ Email:barep.adijayal@gmail.com ${ }^{1)}$ amalia@unuja.ac.id ${ }^{2)}$,ferdyzeng84@gmail.com ${ }^{3)}$
}

\begin{abstract}
Abstrak
Sistem rumah cerdas (Smart Home) adalah sistem aplikasi gabungan antara teknologi dan pelayanan yang dikhususkan pada lingkungan rumah dengan fungsi tertentu yang bertujuan meningkatkan efesiensi, kenyamanan dan keamanan penghuninya. Sistem rumah cerdas terdiri dari perangkat control dan otomatisasi beberapa perangkat atau peralatan rumah yang dapat diakses melalui sebuah komputer.Sistem dibangun dengan menggunakan mikrokontroller arduino dan dengan perangkat pendukung seperti relay, bluetooth, kabel jumper, lampu rumah, smartphone, komputer dan laptop. arduino dijadikan sebagai pengontrol (otak) yang menjalankan perintah yang digunakan untuk mengontrol lampu rumah. Pengontrolan dilakukan melalui aplikasi smartphone, yang terhubung dengan arduino melalui jaringan bluetooth. Relay berfungsi sebagai saklar untuk menyalakan dan memadamkan lampu rumah yang terhubung dengan arduino melalui pin-pin. Melalui pin-pin perintah menyalakan dan memadamkan lampu yang diterima dari arduinol diteruskan ke relay dengan memberikan logika 1 (HIGH) yang berarti menyala dan logika $0(L O W)$ yang berarti padam.Dari hasil pengujian dapat disimpulkan bahwa lampu dapat dinyalakan dan di padamkan melalui aplikasiyang berjalan di android pada arduino yang diakses melalui aplikasi pada smartphone, melalui jaringan bluetooth.
\end{abstract}

Katakunci: Smart Home, arduino uno, bluetooth

\section{Pendahuluan}

\subsection{Latar belakang}

Kondisi pengontrolan instalasi listrik pada kehidupan sebagian besar masyarakat masih tergolong konvensional yaitu relative hanya menggunakan prinsip pengontrolan jarak dekat (manual) atau bisa disebut dengan pengontrolan yang belum mampu dilakukan pada jarak jauh (Hassan, 2010). Perkembangan teknologi dibidang elektronika saat ini memungkinkan pengendalian perangkat listrik secara konvensional menjadi otomatis, salah satu contoh implementasinya disebut Smart Home dengan memanfaatkan suatu alat elektronika yaitu mikrokontroller. Smart Home memiliki sebuah sistem yang didesain memperioritaskan kenyamanan pengunanya.

Sistem smart home diterapkan untuk meningkatkan kenyamanan pengguna dalam mengendalikan peralatan rumah (lampu, kipas, ac,) baik melalui komunikasi kabel maupun nirkabel. Komunikasi kabel berarti peralatan rumah secara fisik terhubung ke server atau pusat control, sementara komunikasi nirkabel berarti peralatan yang terhubung melalui media frekuensi sinyal ke

Barep Adi : Smart Home With Smart ... server atau pusat control (Hisham, Idris, \& Teik, 2014).

Beberapa peralatan Nirkabel seperti Wireless LAN, Infra Merah, Bluetooth, merupakan contoh komunikasi secara nirkabel yang di antaranya memiliki keunggulan yang berbeda. Bluetooth dan Wireless bekerja pada standar yang berbeda. Dimana perbedaan kecepatan transfer data untuk Bluetooth jauh lebih unggul dibandingkan dengan Wireless. Perbandingan antara Infra Merah dan Bluetooth ialah rentang jarak jangkauan yang dimiliki Bluetooth lebih luas (Susanto, 2015). Bluetooth memiliki jangkauan yang lebih luas dan penggunaan sinyal yang lebih efisien di bandingkan dengan perangkat Nirkabel lainnya.

Bluetooth merupakan sebuah protokol Nirkabel dengan daya rendah yang diperkenalkan oleh Bluetooth Spesial Industrial Group (SIG). Selain keunggulan di atas, terdapat keunggulan lain yang dimiliki Bluetooth, Bluetooth menyediakan solusi murah dalam komunikasi nirkabel antara perangkat portable atau genggam pada data rate maksimum 3 Mbps dengan jarak jangkauan \pm 10 meter, beroperasi di 2,4 Ghz ISM band (Susanto, 2015). Dalam pengoperasian, Bluetooth tidak menggunakan koneksi internet dan protokol 
komunikasinya dapat menembus benda. Saat ini semua telephone genggang bersistem operasi android memiliki fitur Bluetooth. Hal ini menjadikan Bluetooth sebagai pilihan membuat smart home yang murah dan efisien (Susanto, 2015).

Memperhatikan kondisi pengontrolan instalasi listrik dalam mengendalikan peralatan listrik rumah tangga pada sebagian besar masyarakat saat ini, serta keunggulan yang tersedia pada Bluetooth, penelitian ini bertujuan membuat alat tentang "Smart Home with Smart Control, berbasis Bluetooth Mikrokontroller ". Alat yang akan dihasilkan dari penelitian ini dapat mengontrol peralatan listrik pada rumah tangga, agar perangkat tersebut dapat dikontrol dari jarak jauh maupun jarak dekat sesuai dengan jangkauan sinyal Bluetooh. Dengan demikian, diharapkan pengguna dapat merasakan kemudahan dan kenyamanan khususnya dalam mengendalikan peralatan listrik rumah tangga baik dari jarak jauh maupun jarak dekat sesuai dengan jangkauan sinyal Bluetooth.

\subsection{Rumusan Masalah}

Berdasarkan latar belakang yang dirumuskan di atas, maka perumusan masalah dalam penelitian ini adalah:

1. Bagaimana membuat alat yang dapat mengontrol perlatan listrik dari area jangkauan sinyal Bluetooth?

2. Bagaimana membuat sistem receiver komunikasi data dari android ke modul Bluetooth HC-06?

\subsection{Tujuan}

Tujuan yang akan dicapai dalam perancangan alat ini adalah :

1. Membuat alat yang dapat mengontrol perlatan listrik dari area jangkauan sinyal Bluetooth.

2. Membuat sistem receiver komunikasi data dari android ke modul Bluetooth HC-06.

3. Membuat inovasi untuk melahirkan suatu produk baru dengan sentuhan teknologi.

\section{Studi pustaka}

\subsection{Penelitian terkait}

Dari beberapa penelitian sebelumnya, yang berkaitan dengan judul Tugas Akhir ini, dimana ada tiga judul namun berbeda bahasan dengan topik penelitian yang sama, yang akan membahas tentang Smart Home with Smart Control, berbasis Bluetooth mikrokontroller untuk dijadikan bahan guna masukan ketepatan dan pelaksanaan sistem yang di uraikan sebagai berikut :

Jurnal pertama diambil dari penelitian terkait berjudul "Saklar Otomatis Berbasis Light Dependent Resistor (ldr) Pada Mikrokontroller Arduino Uno". Pada penelitian ini dijelaskan bahwa seiring perkembangan pembangunan dan teknologi, jumlah kebutuhan daya listrik cenderung naik pesat. Peningkatan kebutuhan daya tersebut dapat diakibatkan oleh penambahan beban baru dan dapat juga disebabkan karena borosnya pemakaian daya listrik.Salah satu upaya penghematan energi listrik ialah dengan pengendalian alat-alat listrik. Pengendalian pada alat-alat listrik khususnya lampu merupakan hal yang penting dalam pengelolaan energi pada suatu tempat, misalnya di rumah atau gedung perkantoran yang memiliki jumlah lampu yang tidak sedikit, atau saat kita sedang pergi keluar kota, lampu terus-menerus dihidupkan agar rumah kita tidak gelap gulita saat malam hari. Otomatisasi atau pengendalian terhadap suatu komponen listrik menjadi jalan keluar untuk masalah ini, disini penulis menggunakan sensor cahaya Light Dependent Resistor (LDR), yang berfungsi sebagai alat yang mengidentifikasi cahaya dan input dari perintah yang akan diteruskan kepada mikrokontroller, dimana mikrokontroller akan memproses perintah sesuai program yang telah dibuat. Relay berfungsi sebagai saklar otomatis yang di hubungkan dengan mikrokontroller, relay menjadi sebuah output perintah dari Mikrokontroller tersebut. Cara kerjanya saat LDR menerima cahaya maka Mikrokontroller akan memproses perintah dengan mengkontak relay menjadi Normaly Open (NO), dan sebaliknya (Tsauqi, El, \& Manuel, 2016).

Jurnal kedua diambil dari penelitian terkait berjudul "Analisis dan Perancangan Prototype Smart Home dengan Sistem Client Server Berbasis Platform Android melalui Komunikasi Wireless" ada penelitian ini dijelaskan bahwa penerapan sebuah smart home yang dapat mengontrol alat-alat listrik melalui komunikasi wireless, memanfaatkan web sebagai server pada suatu komputer yang terhubung dengan mikrokontroller dengan komunikasi melalui wireless terhadap client, mikrokontroller yang digunakan ialah arduino uno, cara kerjanya ialah pada saat client mengirimkan data atau perintah untuk mematikan atau menghidupkan peralatan elektronika, melaui komunikasi secara wireless dan diterima oleh server selanjutnya server mengirimkan perintah tersebut ke sebuah mikrokontroller yang terhubung, mikrokontroller yang menerima perintah 
tersebut memproses output terhadap rangkaian elektronika (Aditya, Hafiduddin, \& Permana, 2016).

Jurnal ketiga diambil dari penelitian terkait berjudul "Smart Home Berbasis IOT" pada penelitian ini dijelaskan bahwa pengontrolan peralatan alat-alat elektronika telah berkembang menggunakan Internet Of Thing (IOT) dengan kendali dan pemantauan pada suatu ruangan. Semua dikendalikan dan dipantau sesuai keinginan pemilik.Sistem smart home ini menggunakan instalasi kabel dan tanpa kabel, sehingga pemanfaatan dan implementasinya sangat cocok untuk terhadap sistem teknologi modern. Alat ini menggunakan dua buah mikrokontroller sebagai pengirim perintah dan pengirim feedback sebagai pemantauan, cara kerja alat ini dengan memanfaatkan komunikasi dari internet, saat smartphone mengirim perintah ke receiver data internet mikrokontroller yaitu modul ESP 8266 lalu mikrokontroller arduino mega melanjutkan perintah yang diterima dari modul ESP 8266 ke perangkat elektronika, dan setelah alat elektronika menyala, mikrokontroller arduino nano mendeteksi adanya tegangan yang mengindikasi bahwa lampu menyala, serta mengirim informasi ke modul ESP 8266 dan di teruskan ke smartphone sebagai feedback (Rachman, 2017).

Jurnal keempat diambil dari penelitian terkait berjudul "Perancangan Prototype Sistem Kendali Lampu menggunakan Handphone Android berbasis Arduino" pada penelitian ini dijelaskan bahwa pengontrolan alat-alat elektronika menggunakan aplikasi android dengan konektifitas Bluetooth yang menjadi penghubung antara android dengan board arduino yang mengontrol peralatan listrik. Hasil dari penelitian ini telah dapat menghidupkan dan mematikan perangkat elektronika. Dari segi efisiensi dan biaya pengaplikasian alat ini sangat menguntungkan, akan tetapi untuk memenuhi kebutuhan pengguna tidak cukup hanya dengan menghidupkan dan mematikan perangkat elektronika saja (Fatoni \& Rendra, 2014)

\subsection{Landasan Teori}

Landasan teori adalah teori yang relevan yang digunakan untuk menjelaskan tentang apa yang akan diteliti dan sebagai dasar untuk memberi jawaban sementara terhadap rumusan masalah yang diajukan (hipotesis) dan penyusunan instrument penelitian.

\subsubsection{Definisi Smart home}

Rumah Cerdas (Smart Home) adalah aplikasi gabungan antara teknologi dan pelayanan yang dikhususkan pada lingkungan rumah dengan fungsi tertentu yang bertujuan meningkatkan keamanan, efisiensi dan kenyamanan penghuninya. Sistem rumah pintar (Smart Home) biasanya terdiri dari perangkat monitoring, perangkat kontrol dan otomatis ada beberapa perangkat yang dapat di akses menggunakan komputer.

Rumah Pintar (Smart Home) merupakan sebuah aplikasi yang dirancang dengan berbantuan komputer yang akan memberikan kenyamanan, keamanan dan penghematan energi yang berlangsung secara otomatis sesuai dengan kendali pengguna dan terprogram melalui komputer pada gedung atau tempat tinggal kita. Teknologi yang dirancangan untuk rumah pintar ini bertujuan untuk memudahkan pemilik rumah dalam memantau kondisi peralatan elektronik yang terhubung dari gadget yang dimiliki (Masykur \& Prasetyowati, 2016).

\subsubsection{Definisi BluetoothHC-06}

Bluetooth adalah protokol komunikasi wireless yang bekerja pada frekuensi radio 2.4 $\mathrm{GHz}$ untuk pertukaran data pada perangkat bergerak seperti PDA, laptop, HP, dan lain-lain. Salah satu hasil contoh modul Bluetooth yang paling banyak digunakan adalah tipe HC-06. Modul Bluetooth HC-06 merupakan salah satu modul Bluetooth yang dapat ditemukan dipasaran dengan harga yang relatif murah. (Budin, 2016)

Modul Bluetooth HC-06 merupakan modul Bluetooth yang bisa menjadi slave ataupun master hal ini dibuktikan dengan bisa memberikan notifikasi untuk melakukan pairing keperangkat lain, maupun perangkat lain tersebut yang melakukan pairing ke modul Bluetooth $\mathrm{HC}$ 06. Untuk mengeset perangkat Bluetooth dibutuhkan perintah-perintah AT Command yang mana perintah AT Command tersebut akan direspon oleh perangkat Bluetooth jika modul Bluetooth tidak dalam keadaan terkoneksi dengan perangkat lain.

\subsubsection{Definisi Mikrokontroller}

Mikrokontroler merupakan sebuah prosesor yang digunakan untuk kepentingan kontrol. Meskipun mempunyai bentuk yang jauh lebih kecil dari suatu komputer pribadi dan komputer mainframe, mikrokontroler dibangun dari elemen-elemen dasar yang sama. Seperti umumnya komputer, mikrokontroler adalah alat 
yang mengerjakan instruksi-instruksi yang diberikan kepadanya. Artinya, bagian terpenting dan utama dari suatu sistem terkomputerisasi adalah program itu sendiri yang dibuat oleh seorang programer. Program ini mengisntruksikan komputer untuk melakukan tugas yang lebih kompleks yang diinginkan oleh programmer Menurut (Agustina, 2016).

\subsubsection{Arduino uno}

Arduino Uno adalah arduino board yang menggunakan mikrokontroler ATmega328. Arduino Uno memiliki 14 pin digital (6 pin dapat digunakan sebagai output PWM), 6 input analog, sebuah 16 $\mathrm{MHz}$ osilator kristal, sebuah koneksi USB, sebuah konektor sumber tegangan, sebuah header ICSP, dan sebuah tombol reset. Arduino Uno memuat segala hal yang dibutuhkan untuk mendukung sebuah mikrokontroler. Hanya dengan menghubungkannya ke sebuah komputer melalui USB atau memberikan tegangan DC dari baterai atau adaptor AC ke DC sudah dapat membuatnya bekerja. Arduino Uno menggunakan ATmega16U2 yang diprogram sebagai USB-to-serial converter untuk komunikasi serial ke komputer melalui port USB (Agustina, 2016).

\subsubsection{Modul Relay}

Relay adalah komponen elektronika berupa saklar elektronik yang digerakkan oleh arus listrik. Secara prinsip, relay merupakan tuas saklar dengan lilitan kawat pada batang besi (solenoid) di dekatnya. Ketika solenoid dialiri arus listrik, tuas akan tertarik karena adanya gaya magnet yang terjadi pada solenoid sehingga kontak saklar akan menutup. Pada saat arus dihentikan, gaya magnet akan hilang, tuas akan kembali ke posisi semula dan kontak saklar kembali terbuka. Relay biasanya digunakan untuk menggerakkan arus/tegangan yang besar misalnya peralatan listrik 4 A/AC $220 \mathrm{~V}$ dengan memakai arus/tegangan yang kecil misalnya $0.1 \mathrm{~A} / 12$ Volt DC (Agustina, 2016).

\subsubsection{Sensor Passive Infrared Receiver (PIR)}

Sensor PIR (Passive Infrared Receiver) adalah sebuah sensor yang biasa digunakan untuk mendeteksi keberadaan manusia. Aplikasi ini biasa digunakan untuk system alarm pada rumah-rumah atau perkantoran. Sensor PIR adalah sebuah sensor yang menangkap pancaran sinyal inframerah yang dikeluarkan oleh tubuh manusia maupun hewan. Sensor PIR dapat merespon perubahanperubahan pancaran sinyal inframerah yang dipancarkan oleh tubuh manusia. Keadaan ruangan dengan perubahan temperatur pada manusia dalam suatu ruangan menjadi nilai awal (set point) yang menjadi acuan dalam system pengontrolan. Perubahan temperatur pada manusia dalam ruangan akan terdeteksi oleh Sensor PIR. Dikatakan PIR (Passive Infrared Receiver) karena sensor ini hanya mengenali lingkungan tanpa adanya energi yang harus dipancarkan. PIR merupakan kombinasi sebuah kristal pyroelectric, filter dan lensa Fresnel (Ayudilah, 2000).

\subsubsection{Sensor suhu}

DHT11 adalah salah satu sensor yang dapat mengukur dua parameter lingkungan sekaligus, yakni suhu dan kelembaban udara (humidity). Dalam sensor ini terdapat sebuah thermistor tipe NTC (Negative Temperature Coefficient) untuk mengukur suhu, sebuah sensor kelembaban tipe resisitif dan sebuah mikrokontroller 8-bit yang mengolah kedua sensor tersebut dan mengirim hasilnya ke pin output dengan format single-wire bi-directional (kabel tunggal dua arah). Jadi walaupun kelihatannya kecil, DHT11 ini ternyata melakukan fungsi yang cukup kompleks. Kita tinggal ambil outputnya aja, untuk kemudian dimasukkan ke sistem kita.

\subsubsection{Catu daya AC to dc (power supply)}

Power Supply adalah alat atau sistem yang berfungsi untuk menyalurkan energi listrik atau bentuk energi jenis apapun yang sering digunakan untuk menyalurkan energi listrik. Secara prinsip rangkaian power Supply adalah menurunkan tegangan AC, menyearahkan tegangan AC sehingga menjadi DC ,menstabilkan tegangan DC, yang terdiri atas Transformator, dioda dan kapasitor/condensator. (Gunawan, 2011)

\section{METODE PENELITIAN}

\subsection{Rancangan dan Pengembangan}

Untuk mencapai tujuan yang diharapkan, pada penelitian ini digunakan model pengembangan yang mengadopsi metode waterfall. Model pengembangan ini digunakan karena kesederhanaan pada setiap tahapannya sehingga prosedur pengembangan yang dibuat menjadi lebih jelas setiap tahapannya. Adapun alur dari model pengembangan tersebut ditunjukan pada Gambar 3.1 


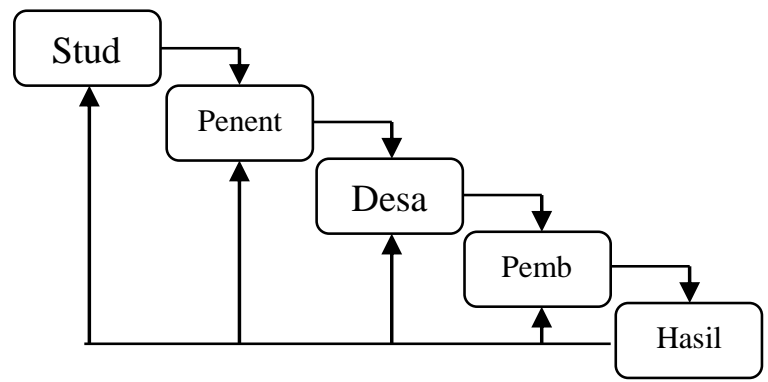

Gambar 3.1 Adopsi model pengembangan waterfall

\subsection{Prosedur pengembangan}

Pada subbab ini dijelaskan langkahlangkah yang dilakukan pada setiap prosedur pada model pengembangan yang digunakan. Berdasarkan Gambar 3.1 prosedur pengembangan

- Papan pcb polos.

- Soder.

- Timah.

- Sedot timah

- Multimeter digital

- Kabel jumper tunggal

- Stang potong dan stang cucut

- Kertas hvs

- Mika plastic

\subsubsection{Desain alat}

Dalam proses ini alat di desain agar lebih tertata dalam penempatan dan lebih menarik. Ada beberapa desain dalam pembuatannya mulai dari rangkaian adaptor hingga rangkaian keseluruhan dari alat ini.

\section{- Desain rangkaian adaptor AC to DC}

Untuk mendesain rangkaian elektronika seperti adaptor, dibutuhkan software khusus yang memang digunakan untuk mendesain rangkaian elektronika. Aplikasi yang akan digunakan kali ini ialah aplikasi Diptrace. Berikut hasil desain melalui aplikasi diptrace tersebut

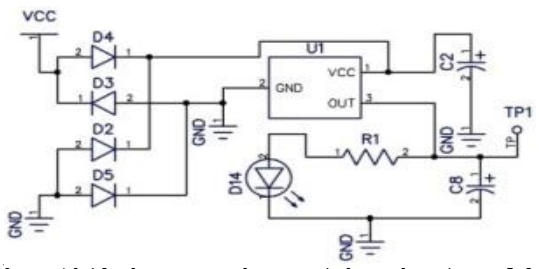

Gambar 3.2 desain skemat1k adaptor AC' to DC

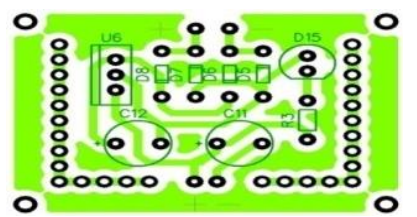

Gambar 3.3 desain layout adaptor AC to DC penelitian ini dapat dijelaskan lebih rinci sebagai berikut.

\subsubsection{Study literatur}

Pembuatan alat ini bergantung pada referensi penelitian sebelumnya sebagaimana telah dijelaskan di pada halaman 2.

\subsubsection{Penentuan alat}

Berikut merupakan alat-alat dan bahan yang digunakan dalam proses pembuatan alat ini:

\section{- Hardware}

- Adaptor AC to DC, berikut komponen yang digunakan di rangkaian adaptor

- Arduino uno r3.

- Modul sensor suhu DHT 11.

- Modul sensor pir.

\section{- Bahan - bahan yang dibutuhkan:}

- Lotion anti nyamuk

- Cairan ferrid clorid

- Bor pcb

- Acrylic

- Cutter

- Gergaji besi

- Amplas halus

- Lem g

- Catpilo

- Desain keseluruhan

Berikut merupakan desain keseluruhan rangkaian smarthome. Dalam desain ini telah terlihat semua alur rangkaian dari adaptor yang menyuplai arduino dan relay. Modul sensor yang telah terhubung ke arduino dan siap untuk digunakan. Desain keseluruhan dapat dilihat pada gambar 3.4 berikut:

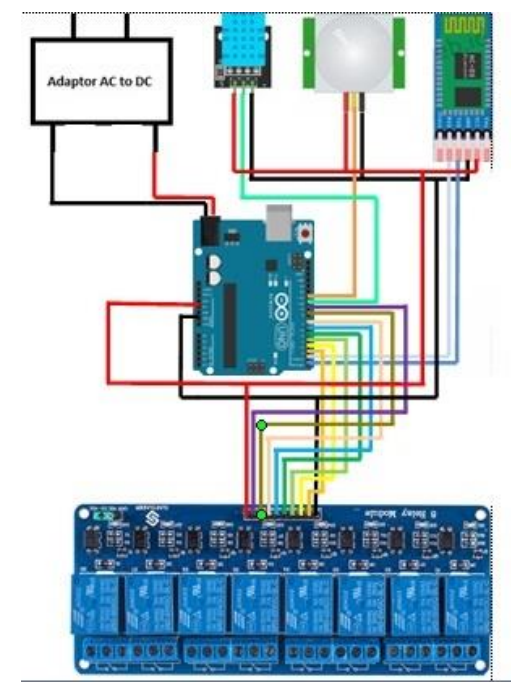

Gambar 3.4 desain keseluruhan smarthome 


\subsubsection{Pembuatan alat}

Ada beberapa tahapan pada proses ini yaitu:

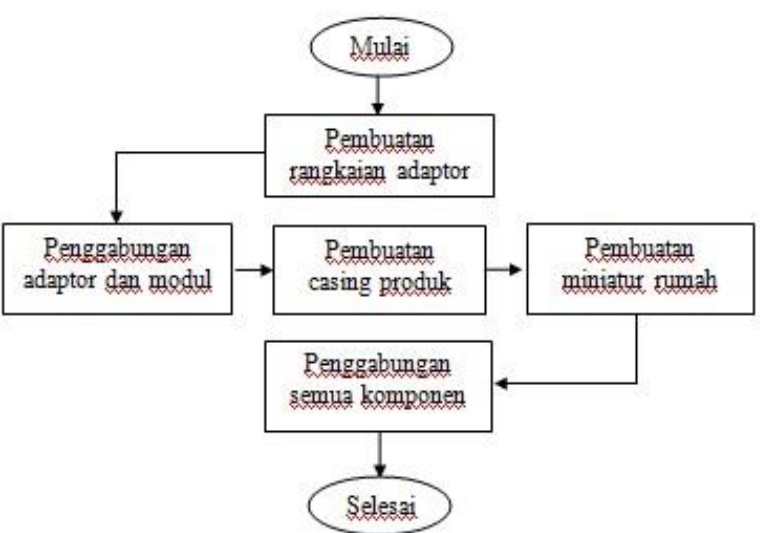

Gambar 3.5 tahapan pembuatan alat

- Pembuatan rangkaian adaptor

- Cetak desain pcb dari rangkaian adaptor menggunakan tinta kering atau dengan mesin fotocopy, jangan menggunakan tinta basah.

- Potong gambar rangkaian yang telah di cetak tersebut dan potong papan pcb sesuai ukuran gambar.

- Bersihkan permukaan pcb dengan amplas halus, kemudian tempelkan gambar di atas papan tembaga pcb dan rekatkan sementara.

- Campurkan lotion anti nyamuk dengan air perbandingan 2:1, oleskan secara merata ke atas permukaan kertas, tutup bagian yang di olesi dengan plastic mika dan segera urut mennggunakan benda yang tumoul seperti uang logam. Pastikan semua tinta kering tadi telah melekat ke papan tembaga pcb.

- Setelah merekat, buka kertas perlahan dan keringkan terlebih dahulu sebelum di masukkan ke dalam cairan ferrid clorid, masukkan pcb ke dalam cairan ferrid clorid dan tunggu beberapa menit, pastikan semua bagian tembaga yang tidak tertutupi tinta larut dalam cairan ini.

- Kemudian ambil papan pcb dari dalam cairan ferrid clorid dan bersihkan dengan menggunakan air. Pastikan semua tinta bersih dan hanya tersisa tembaga jalur rangkaian saja.

- Bor papan pcb di tempat kaki komponen yang akan digunakan, letakan komponen yang diperlukan dan soder menggunakan timah.

- Penggabungan adaptor dan modul
- Setelah rangkaian adaptor dibuat potong papan acrylic sesuai kebutuhan yang di inginkan.

- Susunlah semua modul dan rangkaian sesuai desain yang telah dibuat.

- Hubungkan semua modul dan rangkaian sesuai desain yang telah dibuat.

- Buatlah lubang untuk semua modul dan rangkaian dengan meggunakan bor pada papan acrylic.

- Pasang rangkaian dan modul menggunakan mur dan baut agar melekat pada papan acrylic.

- Pembuatan casing produk

- Potong acrylic sesuai ukuran tempat merekatkan semua komponen tersebut.

- Desain acrylic dalam bentuk sebuah kotak.

- Dan masukkan papan acrylic yang telah di rekatkan modul dan rangkaian kedalam kotak tersebut.

- Buatlah lubang pada kotak untuk memasukkan sumber tegangan AC pada trafo.

- Pembuatan miniatur rumah

- Potong acrylic sesuai ukuran yang telah ditentukan.

- Bentuk menjadi sebuah minatur rumah semirip mungkin.

- Pemasangan led sebagai simulasi lampu dan kipas dc sebagai pendingin ruangan.

- Penggabungan semua komponen

- Letakan alat smarthome dan miniatur di atas papan kayu

- Kemudian mulai hubungkan kabel dari led ke modul relay sebagai simulasi lampu

- Hungunkan kabel dari kipas dc ke relay

- Produk siap di uji coba

\subsubsection{Hasil dan pengujian}

Pada penelitian ini ada beberapa pengujian untuk mengetahui apakah alat ini berjalan. Tujuan pengujian alat ini adalah untuk mengetahui apakah Smart Home ini telah memenuhi kebutuhan pengguna. Adapun beberapa pengujian yang dilakukan sebagai berikut:

- Tegangan pada input dan output pada setiap komponen Smart Home.

- Pengujian jarak konektifitas dan jarak radius maksimum pada perangkat modul Bluetooth hc -06 .

- Pengujian sensor suhu.

- Pengujian sensor pir. 
4. HASIL DAN PEMBAHASAN

4.1. HASIL PENGUJIAN ALAT

4.1.1 Hasil pembuatan alat

Setelah melalui proses pembuatan, telah mencapai pada bagian hasil pembuatan dimana alat telah berhasil dibuat dimana perangkat android telah dapat berkomunikasi dengan modul Smart Home ini dan dapat mengaktifkan atau menonaktifkan peralatan listrik melaui output relay. Berikut merupakan gambar dari Smart Home with Smart Control, berbasis Bluetooth Mikrokontroller:

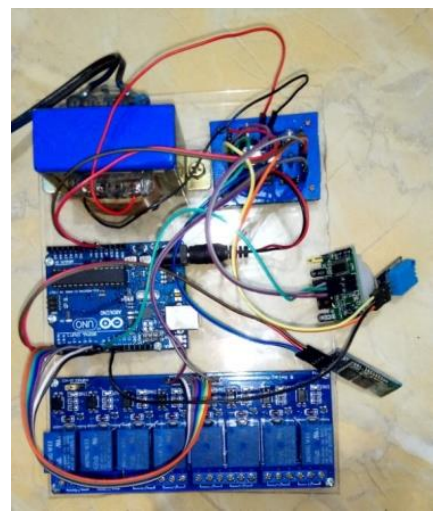

Gambar 4.1 Hasil pembuatan Smart Home

Adapun pengujian-pengujian yang dilakukan terhadap Smart Home tersebut yang akan dibahas pada subbab selanjutnya.

\subsubsection{Pengujian tegangan komponen}

Perangkat keras yang berhasil dibuat dalam penelitian ini adalah Smart Home with Smart Control, berbasis Bluetooth Mikrokontroller. Perangkat keras (Hardware) pada penelitian ini terdiri dari rangkaian adaptor AC to DC, arduino uno r3, modul relay, modul Bluetooth hc-06, modul sensor suhu DHT 11, dan modul sensor pir. Penjelasan hasil pembuatan alat sebagai berikut:

Tabel 4.1 Pengujian tegangan pada komponen smarthome

\begin{tabular}{|c|c|c|}
\hline $\begin{array}{c}\text { Letak yang di } \\
\text { ukur }\end{array}$ & $\begin{array}{c}\text { Tegangan } \\
(\mathbf{V})\end{array}$ & $\begin{array}{c}\text { Jenis } \\
\text { tegangan(AC/ } \\
\text { DC) }\end{array}$ \\
\hline Input Trafo & $201 \mathrm{v}$ & $\mathrm{AC}$ \\
\hline Output Trafo & $10,3 \mathrm{v}$ & $\mathrm{AC}$ \\
\hline Input adaptor & $10,3 \mathrm{v}$ & $\mathrm{AC}$ \\
\hline Output adaptor & $8,97 \mathrm{v}$ & $\mathrm{DC}$ \\
\hline Input arduino & $8,97 \mathrm{v}$ & $\mathrm{DC}$ \\
\hline Output $\mathrm{vcc}$ & $4,92 \mathrm{v}$ & $\mathrm{DC}$ \\
\hline
\end{tabular}

Barep Adi : Smart Home With Smart ...

\begin{tabular}{|c|c|c|}
\hline arduino & & \\
\hline $\begin{array}{c}\text { Input modul } \\
\text { Bluetooth }\end{array}$ & $4,92 \mathrm{v}$ & $\mathrm{DC}$ \\
\hline $\begin{array}{c}\text { Input modul } \\
\text { sensor suhu }\end{array}$ & $4,92 \mathrm{v}$ & $\mathrm{DC}$ \\
\hline $\begin{array}{c}\text { Input modul } \\
\text { sensor pir }\end{array}$ & $4,92 \mathrm{v}$ & $\mathrm{DC}$ \\
\hline $\begin{array}{c}\text { Input modul } \\
\text { relay }\end{array}$ & $4,92 \mathrm{v}$ & $\mathrm{DC}$ \\
\hline \multicolumn{2}{|c|}{ Dari hasil pengujian tegangan diatas } \\
\hline
\end{tabular}

Dari hasil pengujian tegangan diatas tegangan yang dimasuk ke trafo sebesar $201 \mathrm{v}$ AC berdasarkan pengukuran avometer dan tegangan yang di keluarkan trafo sebesar 10,3v AC kemudian tegangan tersebut masuk ke Input adaptor, sebagaimana fungsi adaptor telah dijelaskan pada sub bab 2.2.10. Output adaptor sebesar $8,97 \mathrm{v}$ DC di karenakan adaptor yang digunakan menggunakan ic 7809 yang fungsinya meregulator tegangan yang masuk dan mengeluarkan Output 9v DC. Tegangan Output adaptor kemudian masuk ke arduino sebesar $8,97 \mathrm{v}$. Output vcc pada arduino sebesar 4,92v DC, tegangan ini menyuplai semua modul pada peralatan SmartHome ini. Pengujian tegangan ini dilakukan agar mengetahui apakah nilai tegangan telah sesuai dengan kebutuhan pada komponen pada smarthome ini, pengujian juga dilakukan agar komponen pada SmartHome dapat berjalan semestinya dan bertahan lama.

\subsubsection{Pengujian modul Bluetooth hc-06}

Modul Bluetooth merupakan komponen utama alat ini sebagai transmisi komunikasi data dari android ke arduino dimana pengujian modul ini merupakan pengujian yang paling penting di antara modul lainnya. Pengujian pada komponen modul Bluetooth he -06 ini dilakukan agar dapat mengetahui sejauh mana radius transmisi data dari modul ke hp android yang dapat dilakukan modul ini dan berpengaruh atau tidaknya penghalang dalam kecepatan transmisi data dan jangkauan konektifitas. Pengujian ini sangat penting dilakukan agar dapat mengetahui tipe rumah yang cocok menggunakan alat ini. Berikut tabel hasil pengujian modul Bluetooth hc-06 dengan penghalang tembok dan tidak berpenghalang tembok: 
Tabel 4.2 Pengujian konektifitas Bluetooth hc-06 tidak terhalang tembok

\begin{tabular}{|c|c|c|c|}
\hline $\begin{array}{c}\text { Jarak } \\
\text { (Meter) }\end{array}$ & $\begin{array}{c}\text { Respon } \\
\text { perangkat }\end{array}$ & $\begin{array}{c}\text { Kondisi } \\
\text { relay }\end{array}$ & $\begin{array}{c}\text { Waktu } \\
\text { (second) }\end{array}$ \\
\hline 1 meter & Ya & On & $0,5 \mathrm{~s}$ \\
\hline 2 meter & Ya & On & $0,5 \mathrm{~s}$ \\
\hline 3 meter & Ya & On & $0,5 \mathrm{~s}$ \\
\hline 4 meter & Ya & On & $0,5 \mathrm{~s}$ \\
\hline 5 meter & Ya & On & $0,5 \mathrm{~s}$ \\
\hline 6 meter & Ya & On & $0,5 \mathrm{~s}$ \\
\hline 7 meter & Ya & On & $0,5 \mathrm{~s}$ \\
\hline 8 meter & Ya & On & $0,5 \mathrm{~s}$ \\
\hline 9 meter & Ya & On & $0,5 \mathrm{~s}$ \\
\hline 10 meter & Ya & On & $0,5 \mathrm{~s}$ \\
\hline 11 meter & Ya & On & $0,5 \mathrm{~s}$ \\
\hline 12 meter & Ya & On & $0,5 \mathrm{~s}$ \\
\hline 13 meter & Ya & $O n$ & $0,5 \mathrm{~s}$ \\
\hline 14 meter & Ya & $O n$ & $0,5 \mathrm{~s}$ \\
\hline 15 meter & Ya & $O n$ & $0,5 \mathrm{~s}$ \\
\hline 16 meter & Ya & $O n$ & $0,5 \mathrm{~s}$ \\
\hline 17 meter & Ya & $O n$ & $0,5 \mathrm{~s}$ \\
\hline 18 meter & Ya & $O n$ & $0,8 \mathrm{~s}$ \\
\hline 19 meter & Ya & $O n$ & $0,8 \mathrm{~s}$ \\
\hline 20 meter & Ya & $O n$ & $0,8 \mathrm{~s}$ \\
\hline
\end{tabular}

Tabel 4.3 Pengujian konektifitas Bluetooth hc-06 terhalang tembok

\begin{tabular}{|c|c|c|c|}
\hline $\begin{array}{c}\text { Jarak } \\
\text { (Meter) }\end{array}$ & $\begin{array}{c}\text { Reson } \\
\text { perangkat }\end{array}$ & $\begin{array}{c}\text { Kondisi } \\
\text { relay }\end{array}$ & $\begin{array}{l}\text { Waktu } \\
\text { (second) }\end{array}$ \\
\hline 1 meter & $\mathrm{Ya}$ & On & $0,5 \mathrm{~s}$ \\
\hline 2 meter & $\mathrm{Ya}$ & On & $0,5 \mathrm{~s}$ \\
\hline 3 meter & $\mathrm{Ya}$ & On & $0,5 \mathrm{~s}$ \\
\hline 4 meter & $\mathrm{Ya}$ & On & $0,5 \mathrm{~s}$ \\
\hline 5 meter & $\mathrm{Ya}$ & On & $0,5 \mathrm{~s}$ \\
\hline 6 meter & $\mathrm{Ya}$ & On & $0,5 \mathrm{~s}$ \\
\hline 7 meter & $\mathrm{Ya}$ & On & $0,5 \mathrm{~s}$ \\
\hline 8 meter & $\mathrm{Ya}$ & On & $0,8 \mathrm{~s}$ \\
\hline 9 meter & $\mathrm{Ya}$ & On & $1 \mathrm{~s}$ \\
\hline 10 meter & $\mathrm{Ya}$ & On & $1 \mathrm{~s}$ \\
\hline 11 meter & $\mathrm{Ya}$ & On & $1,2 \mathrm{~s}$ \\
\hline 12 meter & $\mathrm{Ya}$ & On & $1,2 \mathrm{~s}$ \\
\hline 13 meter & $\mathrm{Ya}$ & On & $1,2 \mathrm{~s}$ \\
\hline 14 meter & $\mathrm{Ya}$ & On & $1,2 \mathrm{~s}$ \\
\hline 15 meter & $\mathrm{Ya}$ & On & $1,2 \mathrm{~s}$ \\
\hline 16 meter & Tidak & Off & - \\
\hline 17 meter & Tidak & Off & - \\
\hline 18 meter & Tidak & Off & - \\
\hline 19 meter & Tidak & Off & - \\
\hline 20 meter & Tidak & Off & - \\
\hline
\end{tabular}

dengan dua keadaan berbeda (berpenghalang dan tidak berpenghalang) maka dapat dijelaskan bahwa ketika modul ini tidak berpenghalang radius sinyalnya dapat mencapai 20 meter dengan kecepatan transmisi yang mulai menurun pada saat mencapai jarak 18 meter dan ketika modul ini di uji dengan penghalang radius sinyalnya dapat mencapai 15 meter dengan kecepatan yang mulai menurun pada saat mencapai jarak 8 meter. Dengan adanya pengujian modul ini dapat dijelaskan bahwa penggunaan alat ini cukup baik jika digunakan sebagai SmartHome pada ukuran rumah yang tergolong besar.

\subsubsection{Pengujian sensor suhu}

Sensor suhu digunakan sebagai pendeteksi suhu ruangan yang akan mengkontak relay 7 sebagai Outputnya.Pengujian ini dilakukan untuk mengetahui kepekaan sensor suhu pada perubahan suhu yang terjadi dan mengetahui apakah Output sensor suhu dapat di kontak melalui perintah Bluetooth ketika suhu masih belum mencapai set suhu atau melebihi set suhu.

\section{Tabel 4.4 Pengujian sensor suhu(set suhu $31^{\circ} \mathrm{C}$ )}

\begin{tabular}{|c|c|}
\hline Suhu (celcius) & Kondisi relay 7 \\
\hline $28^{\circ} \mathrm{C}$ & Off \\
\hline $29^{\circ} \mathrm{C}$ & Off \\
\hline $30^{\circ} \mathrm{C}$ & Off \\
\hline $31^{\circ} \mathrm{C}$ & Standby( On/Off) \\
\hline $32^{\circ} \mathrm{C}$ & On \\
\hline $33^{\circ} \mathrm{C}$ & On \\
\hline $34^{\circ} \mathrm{C}$ & On \\
\hline
\end{tabular}

Diatas merupakan hasil pengujian sensor suhu dengan set suhu $31^{\circ} \mathrm{C}$, jika suhu dibawah $31^{\circ} \mathrm{C}$ maka relay 7 akan $O f f$ walaupun relay 7 di $O n$ kan menggunakan konektifitas Bluetooth relay 7 akan Off otomatis karena set suhu yang dibaca oleh sensor belum melebihi $31^{\circ} \mathrm{C}$, jika suhu diatas $31^{\circ} \mathrm{C}$ maka relay 7 akan $O n$ walaupun relay 7 di Off kan menggunakan konektifitas Bluetooth relay 7 akan $O n$ otomatis karena set suhu yang dibaca oleh sensor suhu melebihi $31^{\circ} \mathrm{C}$. Dalam keadaan stanby di suhu $31^{\circ} \mathrm{C}$ relay 7 mengikuti keadaan suhu sebelumnya apabila suhu di bawah $31^{\circ} \mathrm{C}$ relay 7 Off dan apabila suhu diatas $31^{\circ} \mathrm{C}$ relay $7 \mathrm{On}$.

\subsubsection{Pengujian sensor pir}

Sensor pir digunakan untuk mendeteksi adanya pergerakan pada radius tertentu, sensor pir ini digunakan sebagai alat untuk memberikan sinyal suara kepada pemilik rumah apabila ada 
kemungkinan pencurian di ruangan barang berharga. Dalam modul ini sensor pir di pasangkan dengan Output relay 8 yang terhubung ke buzzer. Berikut pengujian sensor pir dengan jarak tertentu pada suatu ruangan:

\section{Tabel 4.5 Pengujian sensor pir}

\begin{tabular}{|c|c|}
\hline Jarak(meter) & Kondisi relay 8 \\
\hline 1 meter & On \\
\hline 2 meter & $O n$ \\
\hline 3 meter & $O n$ \\
\hline 4 meter & $O n$ \\
\hline 5 meter & $O n$ \\
\hline
\end{tabular}

Dari hasil pengujian diatas dapat dijelaskan bahwa sensor pir dapat menangkap sinyal pergerakan dalam jangkauan jarak 1-5 meter, dengan jeda waktu 3 detik sebelum sensor mendeteksi adanya gerakan berikutnya. Jika sensor pir tidak sedang digunakan dapat dimatikan dari saklar yang telah disediakan.

\subsubsection{Pengujian output relay 1 sampai relay 6}

Output yang digunakan untuk mendrive peralatan listrik dalam modul Smart Home ialah relay 1-6 dimana output ini digunakan untuk menghidupkan atau mematikan peralatan listrik melaui perintah dari android langsung. Berikut merupakan tabel pengujiannya:

\section{Tabel 4.6 Pengujian output relay $O N$}

\begin{tabular}{|c|c|c|c|c|}
\hline nama & $\begin{array}{c}\text { Kondisi } \\
\text { pada } \\
\text { aplikasi }\end{array}$ & $\begin{array}{c}\text { Kondisi } \\
\text { pada } \\
\text { modul } \\
\text { Smart } \\
\text { Home }\end{array}$ & $\begin{array}{c}\text { Respon } \\
\text { waktu } \\
\text { dalam } \\
\text { jarak } \\
\text { terdekat }\end{array}$ & $\begin{array}{c}\text { Respon } \\
\text { waktu } \\
\text { dalam } \\
\text { jarak } \\
\text { terjauh }\end{array}$ \\
\hline $\begin{array}{c}\text { Relay } \\
1\end{array}$ & On & On & 0,5 detik & $\begin{array}{c}1,2 \\
\text { detik }\end{array}$ \\
\hline $\begin{array}{c}\text { Relay } \\
2\end{array}$ & On & On & 0,5 detik & $\begin{array}{c}1,2 \\
\text { detik }\end{array}$ \\
\hline $\begin{array}{c}\text { Relay } \\
3\end{array}$ & On & On & 0,5 detik & $\begin{array}{c}1,2 \\
\text { detik }\end{array}$ \\
\hline $\begin{array}{c}\text { Relay } \\
4\end{array}$ & On & On & 0,8 detik & $\begin{array}{c}1,5 \\
\text { detik }\end{array}$ \\
\hline $\begin{array}{c}\text { Relay } \\
5\end{array}$ & On & On & 0,8 detik & $\begin{array}{c}1,5 \\
\text { detik }\end{array}$ \\
\hline $\begin{array}{c}\text { Relay } \\
6\end{array}$ & On & On & 0,9 detik & $\begin{array}{c}1,6 \\
\text { detik }\end{array}$ \\
\hline
\end{tabular}

Tabel 4.7 Pengujian output relay $O N$

\begin{tabular}{|c|c|c|c|c|}
\hline nama & $\begin{array}{c}\text { Kondisi } \\
\text { pada }\end{array}$ & $\begin{array}{c}\text { Kondisi } \\
\text { pada }\end{array}$ & $\begin{array}{c}\text { Respon } \\
\text { waktu }\end{array}$ & $\begin{array}{c}\text { Respon } \\
\text { waktu }\end{array}$ \\
\hline
\end{tabular}

\begin{tabular}{|c|c|c|c|c|}
\hline & aplikasi & $\begin{array}{c}\text { modul } \\
\text { Smart } \\
\text { Home }\end{array}$ & $\begin{array}{c}\text { dalam } \\
\text { jarak } \\
\text { terdekat }\end{array}$ & $\begin{array}{c}\text { dalam } \\
\text { jarak } \\
\text { terjauh }\end{array}$ \\
\hline $\begin{array}{c}\text { Relay } \\
1\end{array}$ & Off & Off & 0,5 detik & 1,2 detik \\
\hline $\begin{array}{c}\text { Relay } \\
2\end{array}$ & Off & Off & 0,5 detik & 1,2 detik \\
\hline $\begin{array}{c}\text { Relay } \\
3\end{array}$ & Off & Off & 0,5 detik & 1,2 detik \\
\hline $\begin{array}{c}\text { Relay } \\
4\end{array}$ & Off & Off & 0,8 detik & 1,5 detik \\
\hline $\begin{array}{c}\text { Relay } \\
5\end{array}$ & Off & Off & 0,8 detik & 1,5 detik \\
\hline $\begin{array}{c}\text { Relay } \\
6\end{array}$ & Off & Off & 0,9 detik & 1,6 detik \\
\hline
\end{tabular}

Dapat dilihat hasil pengujian diatas menunjukan bahwa tidak ada kesalahan dalam menerima dan mengirim komunikasi antara android dengan modul Smart home ini.

\subsection{PEMBAHASAN}

Pada pembuatan alat Smart Home with Smart Control, berbasis Bluetooth Mikrokontroller ini telah berhasil dibuat. Hal ini dapat dilihat pada subbab 4.1.1 terdapat gambar hasil pembuatan yang telah terhubung satu sama lain, hasilnya tidak jauh berbeda dengan gambar desain pada subbab 3.1.3 dimana hanya ada sedikit perubahan pada tata letak penempatan komponen.

Pada subbab 4.1.2 dalam pengujian tegangan pada Input dan Output komponen telah sesuai dengan tegangan yang dibutuhkan komponen-komponen yang meliputi adaptor $\mathrm{AC}$ to DC, Mikrokontroller arduino, modul Bluetooth, modul sensor suhu, modul sensor pir(gerak), dan modul relay. Pengukuran tegangan dilakukan menggunakan avometer digital agar mengetahui detail rincian tegangannya dan mudah dalam pengoperasiannya.

Pada subbab 4.1.3 dibahas tentang hasil pengujian modul Bluetooth, telah didapat hasil bahwa saat ada penghalang dan tidak ada penghalang memiliki dampak berbeda dimana jika tidak ada penghalang jarak transmisi mampu mencapai 20 meter bahkan lebih dengan kecepatan paling lama 0,8 detik saja (menurut tabel 4.2), tetapi jika ada penghalang jarak transmisi mampu mencapai 15 meter dengan kecepatan paling lama 1,2 detik (menurut tabel 4.3). Hal ini membuktikan bahwa pembuatan alat ini telah berhasil sesuai keinginan. 
Pada subbab 4.1.4 dibahas tentang hasil pengujian modul sensor suhu, telah didapat hasil saat suhu berada di bawah set suhu maka relay 7 akan Off atau tidak bertegangan dan saat suhu berada di atas set suhu maka relay 7 akan $O n$ atau bertegangan. Saat relay 7 menerima perintah $O f f$ dari sensor suhu, relay 7 tidak dapat di $O n$ kan melalui aplikasi android yang terkoneksi dengan Bluetooth dan sebaliknya jika relay 7 menerima perintah $O n$ dari sensor suhu, relay 7 tidak dapat di Off kan melaui aplikasi android yang terkoneksi dengan Bluetooth. Kekurangan di modul ini ialah pengaturan set suhu tidak dapat di atur melalui aplikasi melainkan harus melewati coding dari mikrokontroller arduino.

Pada subbab 4.1.5 dibahas tentang hasil pengujian modul sensor pir, telah didapat hasil saat sensor pir di aktifkan sensor pir mendeteksi gerakan yang ada di depannya dan membuat relay $8 O n$, hasil pengujian yang dilakukan di dalam ruangan dengan jarak 1-5 meter membuktikan kinerja sensor pir tetap bekerja normal dalam jeda waktu 3 detik hingga sensor pir mendeteksi ulang gerakan. Pengoperasian sensor pir dilakukan untuk melindungi ruangan dengan barang berharga di dalamnya agar tidak terjadi hal yang tidak diinginkan.

\subsection{Blok diagram}

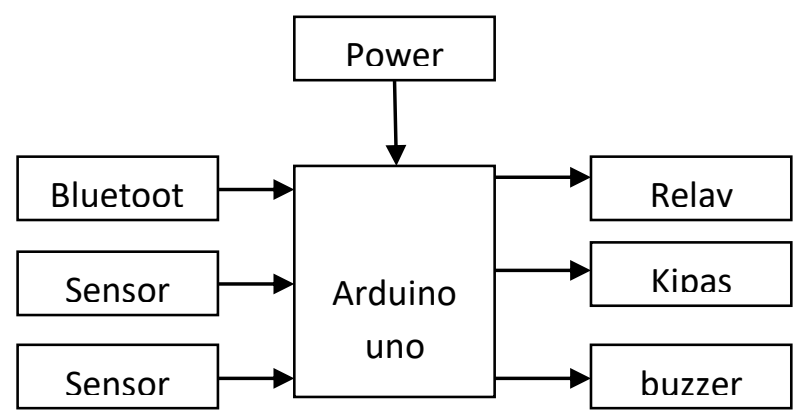

Gambar 4.2 blok diagram smart home

Gambar di atas merupakan blok diagram keseluruhan dari smart home di sebelah kiri arduino merupakan input dari alat ini, dan di sebelah kanan merupakan output dari arduino tersebut. Alat ini menggunakan tegangan dari power supply.

\subsection{Flowchart koding arduino}

Adapun sebelum membuat koding dibutuhkan sebuah flowchart sebagai gambaran alur koding yang berjalan, berikut merupakan flowchart alur koding.

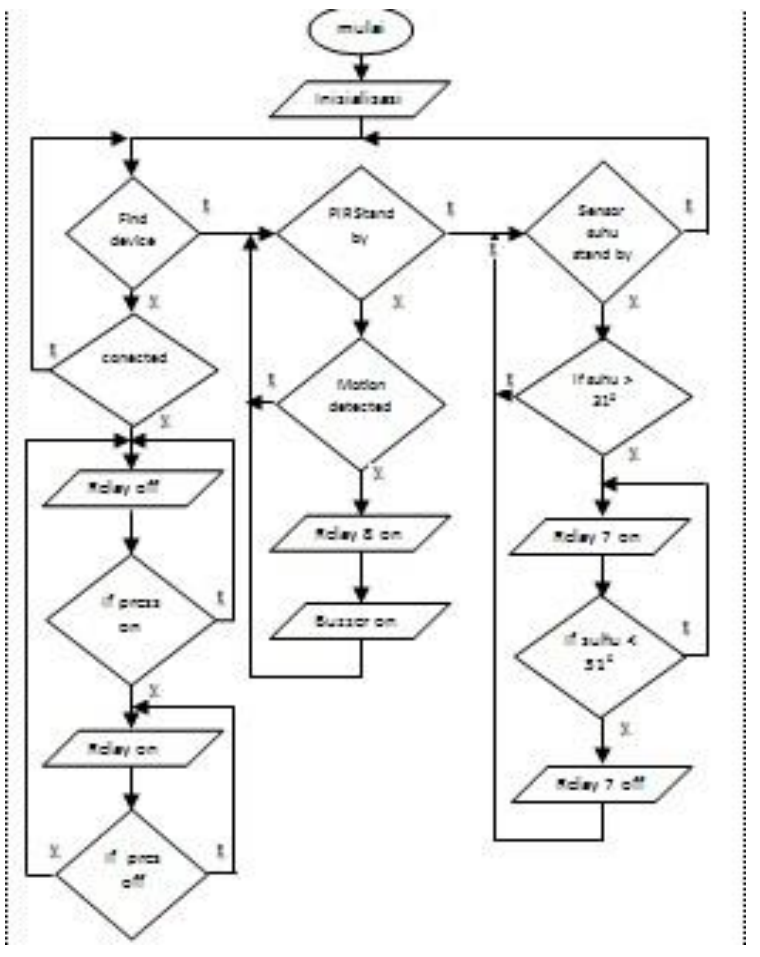

Gambar 4.3 flowchart alur program

\section{KESIMPULAN}

Dari hasil proses pembuatan Smart Home with Smart Control, berbasis Bluetooth Mikrokontroller dapat diambil kesimpulan:

1. Setelah melaui hasil dan pembahasan dapat di ambil kesimpulan bahwa alat telah berhasil dibuat dan dapat berkomunikasi dari aplikasi android ke modul Smart Home dan dapat bekerja dengan sangat baik dalam jarak jangkauan sinyal Bluetooth.

2. Mikrokontroller dapat dikomunikasikan dengan perangkat android melalui komunikasi serial Bluetooth Hc-06.

3. Dapat dikembangkan dengan menambahkan inputan berupa sensor PIR dan sensor suhu DHT11, dikeluarkan dalam bentuk output untuk menjalakan perangkat listrik dari relay.

4. Kekurangan dari alat ini adalah jarak jangkauan sinyal Bluetooth yang terbatas dan nilai set suhu tidak dapat dirubah dari luar melainkan harus melalui koding program yang di upload ke mikrokontroller.

5. Perangkat yang dapat terkoneksi dengan Bluetooth hanya satu perangkat saja, tidak lebih dalam waktu bersamaan 


\section{DAFTAR PUSTAKA}

1. Aditya, F. G., Hafiduddin, \& Permana, A. G. (2016). Analisis dan perancangan prototype smart home dengan sistem client server berbasis platform android melalui komunikasi wireless .

2. Agustina. (2016).

3. Bayu sadewo, A. D., Widasari, E. R., \& Muttaqin, A. (2017). Perancangan pengendali rumah menggunakan smartphone android dengan konektivitas bluetooth.

4. Budin, A. R. (2016). palembang.

5. Community. (2012). Indeks Lengka Syntax/eWolf Comunnity. Yogyakarta: MediaKom.
6. Ernawati, D. (2009). panduan pengunaan diptrace.

7. Fatoni, A., \& Rendra, D. B. (2014). Perancangan Prototype Sistem Kendali Lampu menggunakan Handphone Android berbasis Arduino .

8. Gunawan, P. N. (2011), power supply .

9. Masykur, F., \& Prasetyowati, F. (2016). Aplikasi rumah pintar (smart home) pengendali peralatan elektronik rumah tangga berbasis web.

10. Rachman, F. Z. (2017). Smart home berbasis IOT.

11. Tsauqi, A. K., El, M. H., \& Manuel, I. (2016). Saklar otomatis berbasis light dependent resitor (LDR) pada mikrokontroller arduino uno . 